\title{
The Trilogy of Wild Crops, Traditional Agronomic Practices, and UN-Sustainable Development Goals
}

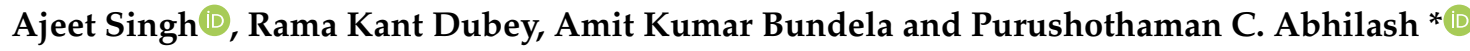 \\ Institute of Environment \& Sustainable Development, Banaras Hindu University, Varanasi 221005, India; \\ ajeetbhu97943@gmail.com (A.S.); ramakant.sls@gmail.com (R.K.D.); amitbundela02@gmail.com (A.K.B.) \\ * Correspondence: pca.iesd@bhu.ac.in; Tel.: +91-9415644280
}

Received: 20 April 2020; Accepted: 28 April 2020; Published: 2 May 2020

\begin{abstract}
The world population is projected to become 10 billion by the end of this century. This growing population exerts tremendous pressure on our finite food resources. Unfortunately, the lion-share of the global calorie intake is reliant upon a handful of plant species like rice, wheat, maize, soybean and potato. Therefore, it is the need of the hour to expand our dietary reliance to nutritionally rich but neglected, underutilized and yet-to-be-used wild plants. Many wild plants are also having ethnomedicinal and biocultural significance. Owing to their ecosystem plasticity, they are adapted to diverse habitats including marginal, degraded and other disturbed soil systems. Due to these resilient attributes, they can be considered for large-scale cultivation. However, proper biotechnological interventions are important for (i) removing the negative traits (e.g., low yield, slow growth, antinutritional factors, etc.), (ii) improving the positive traits (e.g., nutritional quality, stress tolerance, etc.), as well as (iii) standardizing the mass multiplication and cultivation strategies of such species for various agro-climatic regions. Besides, learning the biocultural knowledge and traditional cultivation practices employed by the local people is also crucial for their exploitation. The Special Issue "Wild Crop Relatives and Associated Biocultural and Traditional Agronomic Practices for Food and Nutritional Security" was intended to showcase the potential wild crop varieties of nutritional significance and associated biocultural knowledge from the diverse agroecological regions of the world and also to formulate suitable policy frameworks for food and nutritional security. The novel recommendations brought by this Special Issue would serve as a stepping stone for utilizing wild and neglected crops as a supplemental food. Nevertheless, long-term cultivation trials under various agro-climatic conditions are utmost important for unlocking the real potential of these species.
\end{abstract}

Keywords: agrobiodiversity; biocultural knowledge; crop improvement; dietary diversification; field gene banks; food and nutritional security; planetary healthy diet; traditional agronomic practices

\section{Introduction}

The recently published "EAT-Lancet Commission Report" [1] pinpoints an astonishing fact that the human diet across the globe is not people and planet friendly, as it is far behind the reference level of essential commodities stipulated for a so called "planetary healthy diet" composed of whole grains, vegetables (red, green and orange), fruits and nuts, etc. (www.eatforum.org). The report again pointed that the current global food production itself is not planet friendly as it is produced in an unsustainable manner [2,3]. Therefore, providing a healthy and balanced diet for a growing population is one of the major sustainability challenges for government agencies and policy makers across the world [4-6]. Hence, it is the need of the hour to expand our dietary dependence from a handful of species (i.e., mainly rice, wheat, maize, soybean and potatoes) to locally available and nutritionally rich underutilized wild edibles such as wild leafy vegetables, wild tubers, wild legumes, wild fruits, wild nuts, etc., for a "planetary healthy diet" [5-9]. 
The literature provide evidences that $\sim 7000$ plant species have been reported from the various agro-climatic regions of the world with nutritional or medicinal importance [10,11]. Most of such wild and underutilized species were part of the staple diet of the hunter-gatherers and still many species are the inseparable part of the diet of local people and those who are living in close proximity to nature [10,12-14]. Though some of these species have been widely cultivated for human use and have become a part of the major cropping systems of present-day agriculture $[15,16]$, a vast majority of them are yet-to-be used for large-scale cultivation [5,6] (see Figure 1). As suggested by Pardo-de-Santayana et al. [17], the major factors restricting the day-to-day use of such species are (i) a restricted harvest period, (ii) limited availability due to the lack of market chains, and also due to the (iii) social stigma attached to such species $[7,8]$.
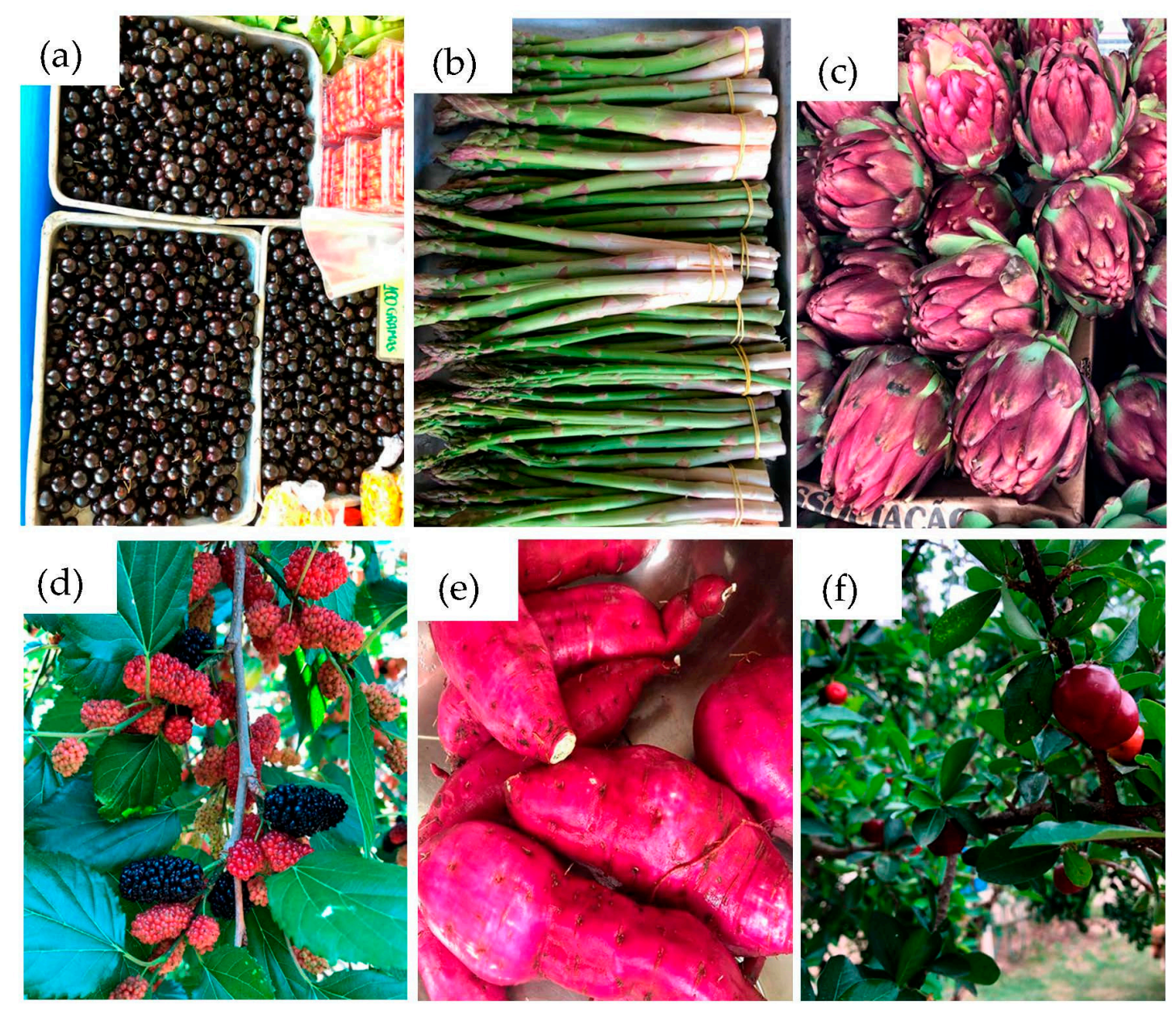

Figure 1. Plants for feeding the future. While there are thousands of plant species that are reported to have food, nutritional and medicinal significance, the current human diet is solely based on a handful of plant species. (a-f) Showing few examples of highly nutritious but not so commonly cultivated species. (a) Jaboticaba or Brazilian grapetree (Plinia cauliflora); (b) Asparagus tender shoot (Asparagus officinalis); (c) Brazilian Alcachofra (Alcachofra sp.); (d) Mulberry (Morus sp.); (e) Sweet potato (Ipomea batatas); and (f) Barbados cherry (Malpighia cauliflora). Photo credit: Prof. Leonardo Fernandes Fraceto, Sao Paulo State University, Sorocaba, Brazil.

Nevertheless, the role of such species for diet complementation is recorded from various parts of the world [5-10]. Moreover, the health and nutritional benefits of some of the species are also available in the literature and even some of the wild species are recognized as functional foods $[18,19]$. Since most of the wild species are bestowed with unusual colors and flavors, they can be used in food industry as a coloring and flavoring agent [10]. Like in the case of modern crop varieties, they also 
contain industrially important bioactive molecules such as ascorbic acid, tartaric acid, malic acid, citric acid, oxalic acid, succinic acid, etc. [10,20,21]. Despite these attributes, they are being neglected and disregarded and their multiple roles are yet to be understood [4]. Therefore, the present editorial was penned to highlight the implications of wild and underutilized plant species for food and nutritional security. The ensuing sections elucidate the trilogy, the content and coverage of the various articles published in this Special Issue as well as the various inventive measures for the sustainable use of wild crops for a good quality of life and human wellbeing.

\section{The Trilogy: Wild Crops, Traditional Agronomic Practices \& UN-SDGs}

The triology of wild crops, traditional agronomic practices and UN-Sustainable Development Goals (UN-SDGs) is illustrated in Figure 2. From this depiction, it is apparent that there is an intricate, explicable and interconnected relationship between wild plants and SDGs.

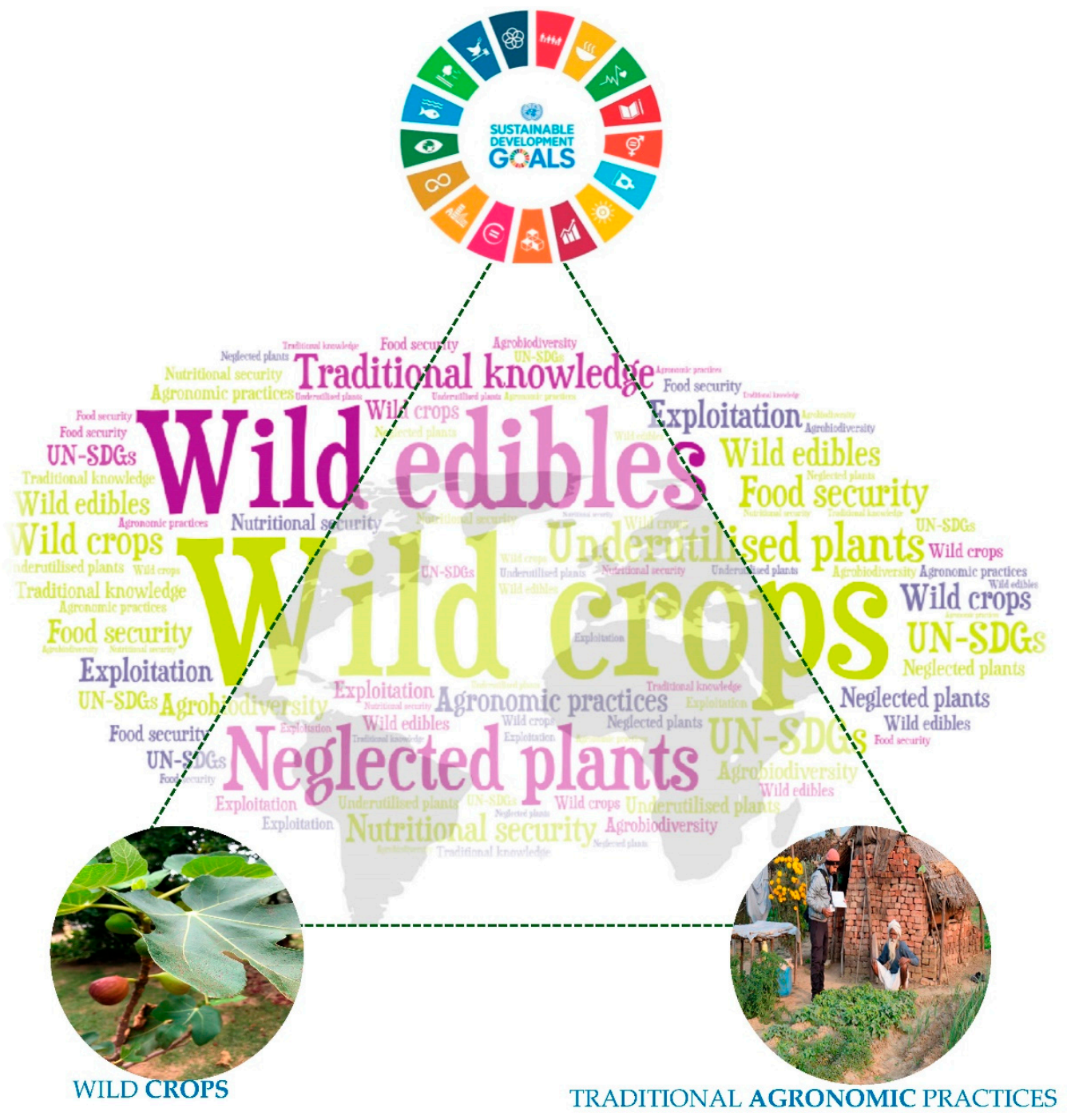

Figure 2. The trilogy of wild crops, traditional agronomic practices and UN-Sustainable Development Goals (UN-SDGs). Though there are many wild crops with food and nutritional significance, their largescale exploitation is mainly limited due to the lack of standard cultivation practices. Therefore, we cannot exploit the intended potential of such species for attaining UN-SDGs. Understanding the biocultural knowledge of the local people as well as learning the traditional agronomic practices employed by them is essential for standardizing the large-scale cultivation practices of such species. Moreover, an integrated understanding is also essential for exploiting their multiple utilities for global sustainability. 
For example, the sustainable use of wild and neglected plants will directly or indirectly help in attaining several SDGs such as no poverty (SDG No. 1), zero hunger (SDG No. 2) and good health and wellbeing (SDG No.3) [4,7-9]. Moreover, the cultivation of such species in family and kitchen gardens will pave an opportunity for empowering women and so achieving gender equality (SDG No. 5). The attainment of food sovereignty through the wise use of wild crops will also reduce inequalities (SDG No. 10) while fostering responsible consumption and production (SDG No. 12). Furthermore, the large-scale adoption of low-input, climate resilient and hardy wild varieties in suitable cropping systems such as intercropping, mixed cropping, boarder cropping, etc., is a part of climate action (SDG No. 13) and encourages agrobiodiversity conservation and thereby the attainment of goal No. 15 (life on land) [7-9]. In a nutshell, the judicious use of wild crops in modern cultivation systems will foster sustainable development.

Despite their nutritional and ecological significances, many of these wild crops are still being neglected and underutilized as stakeholders (such as researchers, farmers and policy makers) are not aware of the agronomic practices required for such species [5,6]. Since modern crops are the result of the thousands of years of domestication, the key investments such as time, money and technology are utmost important for refining the cultivable traits of wild species [4,5]. Moreover, a detailed social and ecological impact assessment must be done to ascertain the socio-ecological complexities behind the introduction of such unknown species into modern agricultural frameworks [5]. So, in order to move further, there is an urgent need to document the traditional agronomic practices employed by the indigenous and local community and pass on these dying wisdoms to mainstream farmers for further refinement through field validation. Biotechnological interventions (including conventional and modern biotechnological approaches) are important for standardizing suitable agronomic practices for their large-scale cultivation in various agro-climatic regions of the world. Moreover, crop improvement is also essential for further enhancing the nutritional qualities and palatability of such species and also for removing the anti-nutritional factors if any $[8,9]$. Importantly, such crop improvement initiatives must be done in a participatory mode (i.e., with the involvement of farmers) to optimize crop-specific and site-specific agronomic practices of these lesser known edibles for human welfare. Without these initiatives, unlocking the real potential of wild species for food and nutritional security will be a mirage rather than a reality.

\section{From Exploration to Crop Improvement: The Content and Coverage of the Special Issue}

The current Special Issue is an assemblage of the diverse topics related to wild crops and their sustainable exploitation like agrobiodiversity, adaptive agronomic practices, biocultural knowledge, crop improvement programs, dietary diversification, field gene banks, food and nutritional security, genetic diversity, UN-Sustainable Development Goals, wild crop varieties and traditional agronomic practices, among others. The ensuing part provides a glimpse of the various articles published in this Special Issue.

Harouna et al. [22] investigated the preferences and perspectives of local farmers in the Arusha and Kilimanjaro regions in Tanzania regarding the use of wild Vigna legumes such as Vigna racemosa, $V$. reticulata, $V$. vexillata and $V$. ambacensis. While all of these four species have multiple utilities like food, feed and medicinal uses as well as other environmental significance such as a mulching agent and also for controlling soil erosion, very few farmers of the study regions $(26 \%-28 \%)$ were actually aware of the significance of these species. The takeaways clearly ascertain the fact that exploration as well as popularization of such lesser known species is utmost important for their successful exploitation. Similarly, Coulibaly et al. [23] studied the farmers' preferences over the genetic resources of wild Kersting's groundnut (Macrotyloma geocarpum) in Burkina Faso and Ghana. The field results revealed that the famer's preferences were influenced by their sociocultural background and also depended upon the promising traits of the genetic resources such as the yield potential, drought tolerance and pest resistance. 
In addition to wild pulses and legumes, neglected vegetables like the spider plant (Gynandropsis gynandra L. (Briq.) are also important species of food and nutritional relevance in sub-Saharan Africa. Chataika et al. [24] explored the diversity and domestication status of the spider plant in northern Namibia for identifying the client-preferred traits for a customized breeding program. Extensive field experiments for understanding the agro-morphological variations in wild crops are also important for selecting elite germplasms. In this way, Harouna and co-workers [25] conducted an extensive field trial of 160 accessions of wild Vigna in Tanzania and studied the variations in the quantitative as well as qualitative traits (15 each) for identifying the superior accessions for breeding and crop improvements. Identifying the most suitable habitats for the large-scale cultivation of wild crops as well as predicting their growth response under futuristic climatic condition is a changing paradigm in wild crop research. Interestingly, Ratnayake and co-authors [26] studied the potential range changes of four neglected and underutilized fruit species like Aegle marmelos, Annona muricata, Limonia acidissima and Tamarindus indica in Sri Lanka under different climate change scenarios and mapped their high-potential agro-ecological regions for large-scale cultivation. The study underpins the significance of predictive modelling as an effective tool for identifying the most suitable regions (Figure 3) of neglected species for large-scale exploitation.

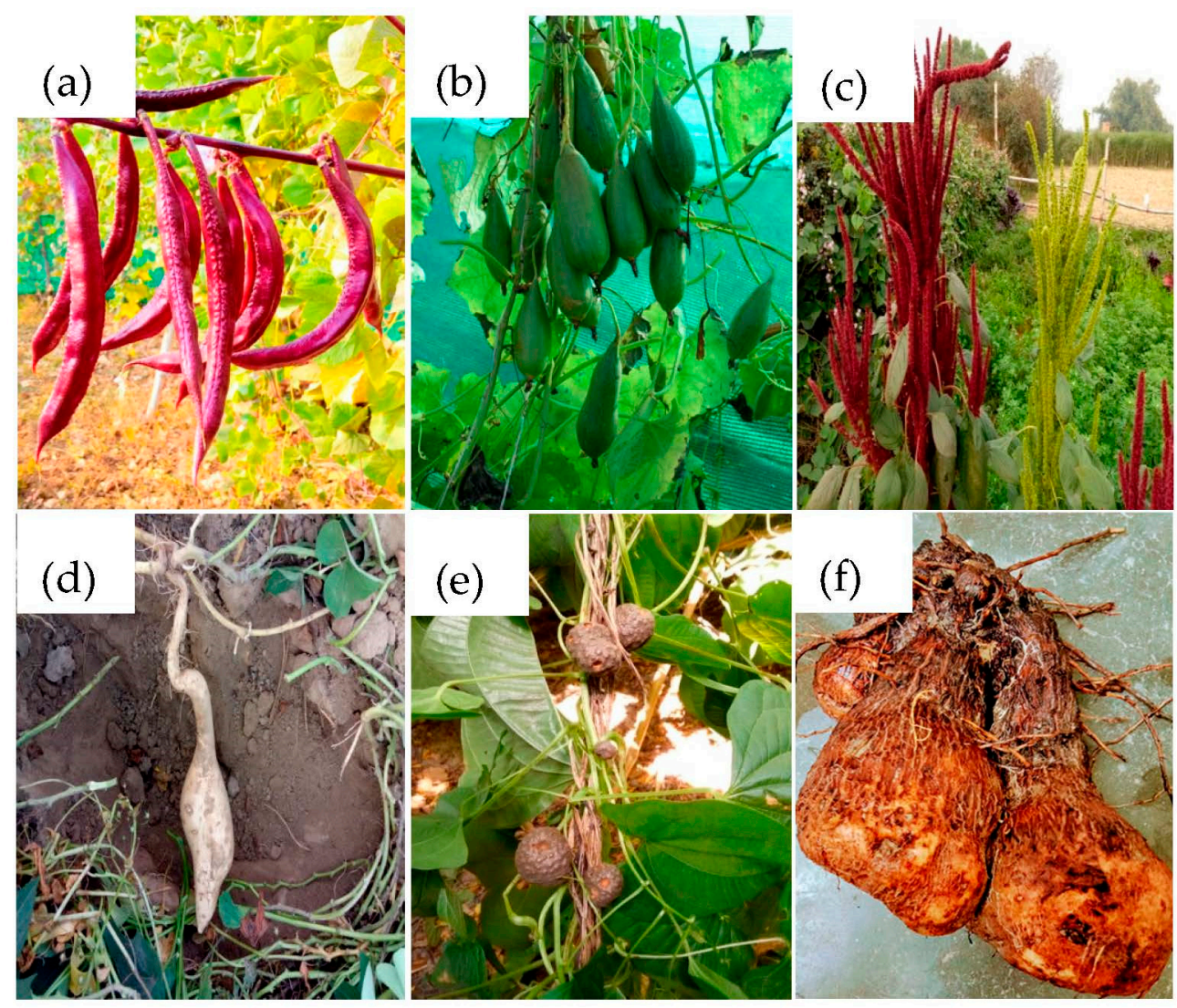

Figure 3. Predictive modelling is essential for identifying the best suitable agro-ecological regions of various neglected and wild species for large-scale cultivation and popularization. Moreover, apart from the habitat requirement, the biocultural preferences are also considered for promoting a particular wild edible for a particular region. Some of the candidate species for habitat suitability mapping and large-scale cultivation: (a) Lablab or Hyacinth bean (Lablab purpureus); (b) wild ridge gourd (Luffa acutangular); (c) pseudo-cereal or red amaranth (Amaranthus cruentus); (d) wild sweet potato (Ipomoea batatas); (e) air potato (Dioscorea bulbifera); and (f) purple yam (Dioscorea alata).

The medicinal and nutraceutical uses of three traditional leafy vegetables, viz. Crassocephalum crepidioides, Launaea taraxacifolia and Vernonia amygdalina Del., in southern Benin and the legacy of the 
transmission of traditional and local knowledge from parents to children were studied by Akakpo and Achigan-Dako [27]. Since traditional leafy vegetables are an integral part of the African diet, the majority of these leafy vegetables (for example Bidens pilosa, Brassica carinata, Gynandropsis gynandra, Corchorus spp., Launaea taraxacifolia, Talinum triangulare, etc.) are not domesticated yet $[27,28]$. Some of the traditional leafy vegetables also exhibit seed dormancy. Therefore, understanding the molecular mechanisms that underpin the seed dormancy is essential for devising a suitable breeding program. In this context, Sohindji and co-workers [28] used Gynandropsis gynandra as a model plant to elucidate the mechanisms of seed dormancy in traditional leafy vegetables and proposed suitable strategies for the molecular breeding of wild leafy vegetables with improved germination.

Innovative breeding approaches are also essential for improving the quality and adaptability of wild crops. For example, Alvarez and Guzman [29] studied the genetic variation in the high molecular weight glutenin subunits (Glu-A1, Glu-B1 and Glu-D1) in three neglected and underutilized wheat crops such as club wheat (Triticum aestivum), macha wheat (T. aestivum ssp. macha) and Indian dwarf wheat (T. aestivum L. ssp. sphaerococcum) for quality improvements. Similarly, Jency et al. [30] reported induced mutagenesis using ethyl methane sulphonate (EMS) and gamma radiation to develop photosynthetically efficient and lodging-resistant kodo millet (Paspalum scrobiculatum) for large-scale cultivation in peninsular India.

The standardization of agronomic practices is also important for improving the nutritional quality and other featured traits in wild crops (Figure 4). Moreover, previous studies have also reported that such innovative agronomic practices can also improve the soil quality and microbial activity [31-33]. Brtnicky et al. [34] proved that the long-term addition of biochar resulted in increases in the microbial biomass' carbon and microbial community abundance, and soil dehydrogenase activity in luvisols of arable land in the Czech Republic.
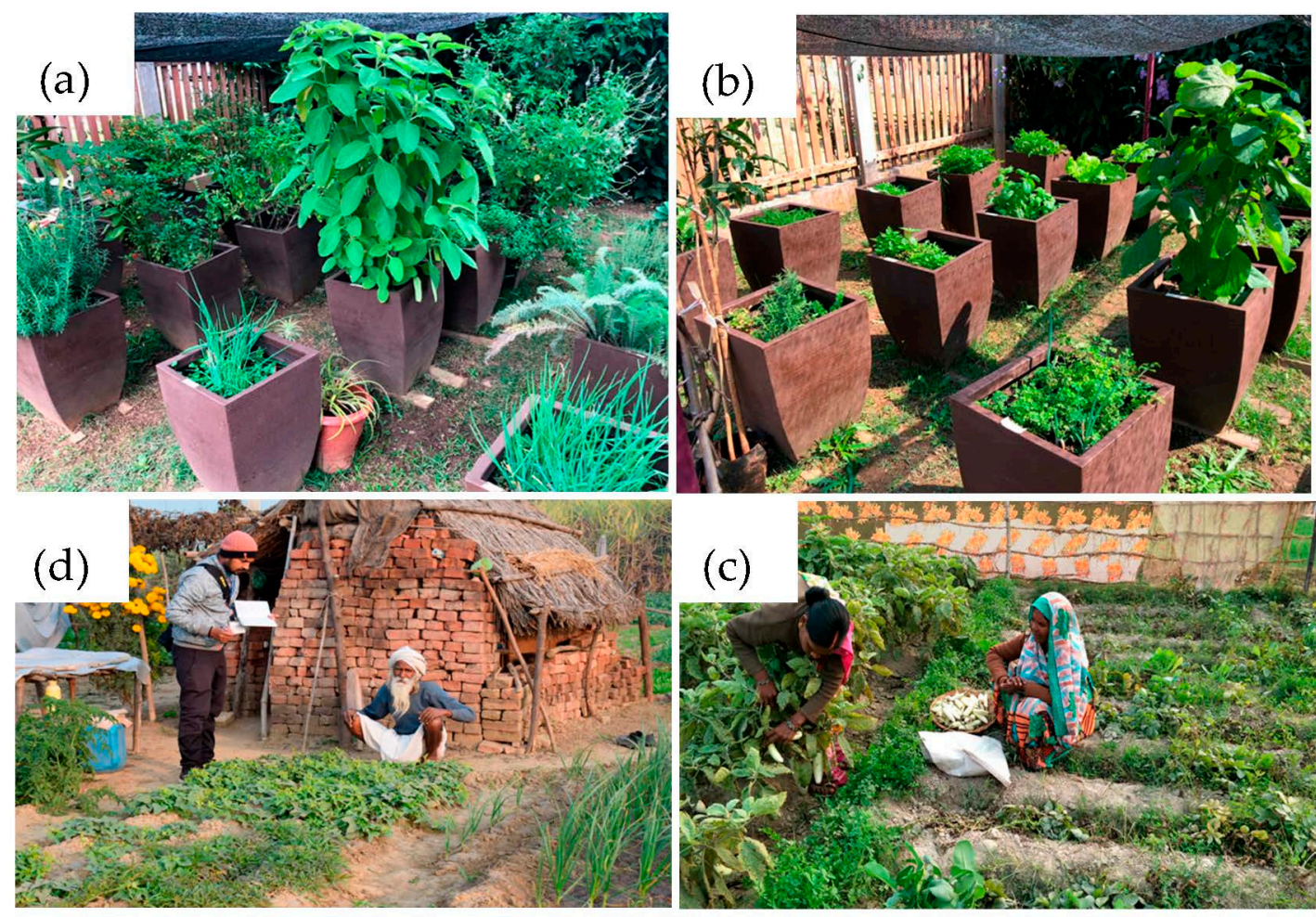

Figure 4. Standardization of suitable agronomic practices as well as the optimization of suitable cultivation models are essential for the large-scale cultivation and also for the successful introduction of such species into family and kitchen gardens. $(\mathbf{a}, \mathbf{b})$ The cultivation of traditional species in the backyard garden of Prof. Leonardo Fernandes Fraceto in Sorocaba, Sao Paulo, Brazil and (c,d) the wild species in the kitchen garden of local farmers in Rajgarh block, Mirzapur, Uttar Pradesh, India. 
Chanthani et al. [35] demonstrated the positive effect of the seaweed extract from Ulva flexuosa on the seed priming of wild tomatoes for increasing the seed germination, growth and yield. The experimental results confirmed that the application of seaweed extract as a biostimulant has increased the nutritional and biochemical profile of the test plant by several folds, i.e., TSS (93\%), phenol (92\%), lycopene (12\%) and ascorbic acid (86.8\%). Similarly, Michalska-Ciechanowska and colleagues [36] moderated the inulin and polyphenolics contents in three cultivars of Jerusalem artichoke (Helianthus tuberosus L.) by optimizing the potassium $(\mathrm{K})$ application. The study on the effect of the different growing conditions (i.e., greenhouse and open field) on the quality and phytochemical composition of edible wall rocket (Diplotaxis erucoides) revealed that the field conditions gave better results than the controlled conditions [37]. All these studies have given novel insights regarding the cultivation and management of lesser known edibles for human wellbeing.

In another work, Dwivedi et al. [38] reviewed the need of tapping unique traits in heirloom cultivars such as crop growth and yield governing attributes, biotic and abiotic stress tolerance traits as well as traits governing proximate composition, flavor, color, etc., into local elite cultivars through suitable breeding programs. Interestingly, the importance of creating inventive market channels, for example farmer-breeder-chef collaborations and seed-saver organizations for promoting and popularizing heirloom cultivars, are also suggested by them. Similarly, in the article on Local Solutions for Sustainable Food Systems: The Contribution of Orphan Crops and Wild Edible Species, Borelli and her colleagues [39] examined the "role of locally available; affordable and climate-resilient orphan crops, traditional varieties and wild edible species to support local food system transformation" in Brazil, Kenya, Guatemala, India, Mali, Sri Lanka and Turkey.

For the sustainable food system transition based on orphan crops and wild edibles, authors have basically employed a "three-pronged approach to (i) increase the evidence of the nutritional value and biocultural importance of these foods, (ii) better link the research to policy to ensure these foods are considered in national food and nutrition security strategies and actions, and (iii) improve consumer awareness of the desirability of these alternative foods so that they may more easily be incorporated in diets, food systems and markets" [39] (Figure 5).

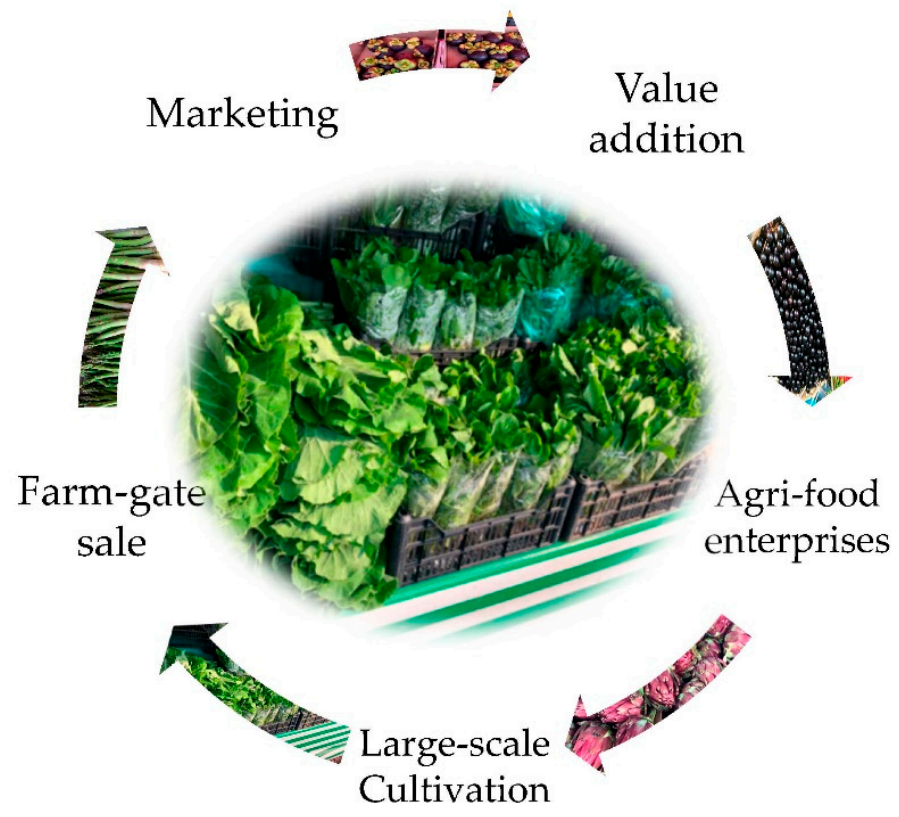

Figure 5. Creating marketing channels including the provisions for value-addition and also the creation of suitable agri-food enterprises based on wild, neglected and underutilized crops are essential for a sustainable food system transition. The availability and affordability of these wild edibles will gradually increase the adoption and acceptance of these lesser known edibles among the community. 
The deliberations of the above two reviews lead to a common thread that apart from the exploration, documentation and large-scale exploitation of various wild and lesser known edibles for diet supplementation, the creation of market channels including supply-chain management and value additions are the key aspect governing the success of a transition towards a wild, neglected and underutilized edibles-based food system [38,39]. Community mobilization can be done for enhancing the sale of these items at the farm-gate level itself. Since a majority of these lesser-known edibles are seasonal, value-addition will provide an opportunity for establishing agri-food start-ups.

Last but not least, the crux of the overall issue was discussed by Singh et al. [40] and proposed four inventive strategies for the domestication of undomesticated crops for global food and nutritional security such as "(i) exploring the unexplored, (ii) refining the unrefined traits, (iii) cultivating the uncultivated, and (iv) popularizing the unpopular for the sustainable utilization". Furthermore, authors have also recommended the need of starting coordinated efforts at the national, regional and international level, especially under the aegis of UN organizations and internationally renowned agricultural institutions, policy makers, governments and voluntary organizations to conserve, promote and popularize wild, neglected and underutilized species for the wellbeing of both people and the planet [40].

\section{Conclusions}

In conclusion, neglected, wild, underutilized, traditional or orphan crops possess enormous nutritional, nutraceutical, industrial, ethnomedicinal and biocultural significance, and therefore their sustainable utilization will directly or indirectly lead to sustainable development. While multiple utilities of some of the species are known to local framers and the scientific community, the real potential of the vast majority of such species is unknown. Therefore, inventive measures are essential for the exploration, documentation and bioprospecting of such species for identifying their multipurpose benefits as well as the optimization of agronomic practices including suitable crop improvement programs that are essential for unlocking their real potential for human heath and wellbeing.

Author Contributions: Conceptualization, A.S., R.K.D. and P.C.A.; writing-original draft preparation, A.S., R.K.D, A.K.B. and P.C.A.; writing-review and editing, A.S., R.K.D., A.K.B. and P.C.A.; supervision, P.C.A. All authors have read and agreed to the published version of the manuscript.

Acknowledgments: Authors are grateful to Yanping Mou, Agronomy office for their continuous support and help for the successful edition of this Special Issue. We are also grateful to all authors of this Special Issue for their highly interesting contributions. We are also grateful to all the reviewers for their invaluable help and support for selecting suitable manuscripts and also the timely publication of this Special Issue.

Conflicts of Interest: The authors declare no conflict of interest.

\section{References}

1. Willett, W.; Rockström, J.; Loken, B.; Springmann, M.; Lang, T.; Vermeulen, S.; Garnett, T.; Tilman, D.; Wood, A.; Clark, M.; et al. Food in the Anthropocene: The EAT-Lancet Commission on Healthy Diets from Sustainable Food Systems. Lancet 2019, 393, 447-492. [CrossRef]

2. Dubey, P.K.; Abhilash, P.C. Agriculture in a changing climate. J. Clean. Prod. 2016, 100, 1046-1047. [CrossRef]

3. Dubey, P.K.; Singh, G.S.; Abhilash, P.C. Adaptive Agricultural Practices: Building Resilience in a Changing Climate; Springer: Berlin/Heidelberg, Germany, 2019; ISBN 978-3-030-15518-6. [CrossRef]

4. Singh, A.; Abhilash, P.C. Agricultural biodiversity for sustainable food production. J. Clean. Prod. 2018, 172, 1368-1369. [CrossRef]

5. Singh, A.K. Wild Relatives of Cultivated Plants in India. In A Reservoir of Alternative Genetic Resources and More; Springer: Berlin/Heidelberg, Germany, 2017; ISBN 9789811051166.

6. Hunter, D.; Guarino, L.; Spillane, C.; McKeown, P.C. (Eds.) Routledge Handbook of Agricultural Biodiversity; Routledge: Thames, UK, 2017; p. 692, Price 175, 00£; ISBN 9780415746922.

7. Singh, A.; Dubey, P.K.; Chaurasiya, R.; Mathur, N.; Kumar, G.; Bharati, S.; Abhilash, P.C. Indian spinach: An underutilized perennial leafy vegetable for nutritional security in developing world. Energ. Ecol. Environ. 2018, 3, 195-205. [CrossRef] 
8. Singh, A.; Dubey, P.K.; Abhilash, P.C. Food for thought: Putting wild edibles back on the table for combating hidden hunger in developing countries. Curr. Sci. 2018, 115, 611-613. [CrossRef]

9. Singh, A.; Abhilash, P.C. Varietal dataset of nutritionally important Lablab purpureus (L.) sweet from Eastern Uttar Pradesh, India. Data Brief 2019, 24, 103935. [CrossRef]

10. Sánchez-Mata, M.C.; Cabrera Loera, R.D.; Morales, P.; Fernández-Ruiz, V.; Cámara, M.; Marqués, C.D.; de Santayana, M.P.; Tardío, J. Wild vegetables of the Mediterranean area as valuable sources of bioactive compounds. Genet. Resour. Crop Evol. 2012, 59, 431-443. [CrossRef]

11. Ghane, S.G.; Lokhande, V.H.; Ahire, M.L.; Nikam, T.D. Indigofera glandulosa Wendl. (Barbada) a potential source of nutritious food: Underutilized and neglected legume in India. Genet. Resour. Crop Evol. 2010, 57, 147-153. [CrossRef]

12. Termote, C.; Van Damme, P.; Dhed'a Djailo, B. Eating from the wild: Turumbu, Mbole and Bali traditional knowledge on non-cultivated edible plants, District Tsh- opo, DRCongo. Genet. Resour. Crop Evol. 2011, 58, 585-618. [CrossRef]

13. Vazquez-Garcia, V. Gender, ethnicity, and economic status in plant management: Uncultivated edible plants among the Nahuas and Popolucas of Veracruz, Mexico. Agric. Hum. Values 2008, 25, 65-77. [CrossRef]

14. Price, L.L. Farm womens rights and roles in wild plant food gathering and management in North-East Thailand. In Women and Plants. Gender Relations in Biodiversity Management and Conservation; Howard, P.L., Ed.; Zed Books and IDRC: London, UK, 2003; pp. 101-114.

15. Bharucha, Z.; Pretty, J. The roles and values of wild foods in agricultural systems. Philos. Trans. R. Soc. B 2000, 365, 2913-2926. [CrossRef] [PubMed]

16. Hammer, K.; Knüpffer, H.; Laghetti, G.; Perrino, P. Seeds from the past. In A Catalogue of Crop Germplasm in Central and North Italy; IG of CNR: Bari, Italy, 1999.

17. Pardo-de-Santayana, M.; Tardío, J.; Blanco, E.; Carvalho, A.M.; Lastra, J.J.; San Miguel, E.; Morales, R. Traditional knowledge on wild edible plants in the northwest of the Iberian Peninsula (Spain and Portugal): A comparative study. J. Ethnobiol. Ethnomed. 2007, 3, 27. [CrossRef] [PubMed]

18. Ansari, N.M.; Houlihan, L.; Hussain, B.; Pieroni, A. Anti- oxidant activity of five vegetables traditionally consumed by South-Asian Migrants in Bradford, Yorkshire, UK. Phytother. Res. 2005, 19, 907-911. [CrossRef] [PubMed]

19. Salvatore, S.; Pellegrini, N.; Brenna, O.V.; Del Rio, D.; Frasca, G.; Brighenti, F.; Tumino, R. Antioxidant characterization of some Sicilian edible wild greens. J. Agric. Food Chem. 2005, 53, 9465-9471. [CrossRef]

20. Phillips, K.M.; Tarrago-Trani, M.T.; Gebhardt, S.E.; Exler, J.; Patterson, K.Y.; Haytowitz, D.B.; Pehrsson, P.R.; Holden, J.M. Stability of vitamin C in frozen raw fruit and vegetable homogenates. J. Food Compost. Anal. 2010, 23, 253-259. [CrossRef]

21. Oliveira, A.P.; Pereira, J.A.; Andrade, P.B.; Valentão, P.; Seabra, R.M.; Silva, B.M. Organic acids composition of Cydonia oblonga Miller leaf. Food Chem. 2008, 111, 393-399. [CrossRef]

22. Harouna, D.V.; Venkataramana, P.B.; Matemu, A.O.; Ndakidemi, P.A. Wild Vigna legumes: Farmers' perceptions, preferences, and prospective uses for human exploitation. Agronomy 2019, 9, 284. [CrossRef]

23. Coulibaly, M.; Agossou, C.O.; Akohoué, F.; Sawadogo, M.; Achigan-Dako, E.G. Farmers' Preferences for Genetic Resources of Kersting's Groundnut Macrotyloma geocarpum (Harms) Maréchal and Baudet] in the Production Systems of Burkina Faso and Ghana. Agronomy 2020, 10, 371. [CrossRef]

24. Chataika, B.; Akundabweni, L.; Achigan-Dako, E.G.; Sibiya, J.; Thomas, B. Diversity and Domestication Status of Spider Plant (Gynandropsis gynandra, L.) amongst sociolinguistic groups of Northern Namibia. Agronomy 2020, 10, 56. [CrossRef]

25. Harouna, D.V.; Venkataramana, P.B.; Matemu, A.O.; Ndakidemi, P.A. Agro-morphological exploration of some unexplored wild vigna legumes for domestication. Agronomy 2020, 10, 111. [CrossRef]

26. Ratnayake, S.S.; Kumar, L.; Kariyawasam, C.S. Neglected and Underutilized Fruit Species in Sri Lanka: Prioritisation and understanding the potential distribution under climate change. Agronomy 2020, 10, 34. [CrossRef]

27. Akakpo, A.D.; Achigan-Dako, E.G. Nutraceutical uses of traditional leafy vegetables and transmission of local knowledge from parents to children in Southern Benin. Agronomy 2019, 9, 805. [CrossRef]

28. Sohindji, F.S.; Sogbohossou, D.E.; Zohoungbogbo, H.P.; Houdegbe, C.A.; Achigan-Dako, E.G. Understanding molecular mechanisms of seed dormancy for improved germination in traditional leafy vegetables: An overview. Agronomy 2020, 10, 57. [CrossRef] 
29. Alvarez, J.B.; Guzmán, C. Recovery of wheat heritage for traditional food: Genetic variation for high molecular weight glutenin subunits in neglected/underutilized wheat. Agronomy 2019, 9, 755. [CrossRef]

30. Jency, J.P.; Rajasekaran, R.; Singh, R.K.; Muthurajan, R.; Prabhakaran, J.; Mehanathan, M.; Prasad, M.; Ganesan, J. Induced mutagenesis enhances lodging resistance and photosynthetic efficiency of Kodomillet (Paspalum Scrobiculatum). Agronomy 2020, 10, 227. [CrossRef]

31. Dubey, R.K.; Dubey, P.K.; Chaurasia, R.; Singh, H.B.; Abhilash, P.C. Sustainable agronomic practices for enhancing the soil quality and yield of Cicer arietinum L. under diverse agroecosystems. J. Environ. Manag. 2020, 262, 110284. [CrossRef]

32. Dubey, R.K.; Dubey, P.K.; Abhilash, P.C. Sustainable soil amendments for improving the soil quality, yield and nutrient content of Brassica juncea (L.) grown in different agroecological zones of eastern Uttar Pradesh. Soil Tillage Res. 2019, 195, 104418. [CrossRef]

33. Dubey, R.K.; Tripathi, V.; Prabha, R.; Chaurasia, R.; Singh, D.P.; Rao, C.H.; El-Keblawy, A.; Abhilash, P.C. Unravelling the Soil Microbiomes: Perspectives for Environmental Sustainability; Springer-Nature: Berlin/Heidelberg, Germany, 2020.

34. Brtnicky, M.; Dokulilova, T.; Holatko, J.; Pecina, V.; Kintl, A.; Latal, O.; Vyhnanek, T.; Prichystalova, J.; Datta, R. Long-term effects of biochar-based organic amendments on soil microbial parameters. Agronomy 2019, 9, 747. [CrossRef]

35. Chanthini, K.M.P.; Stanley-Raja, V.; Thanigaivel, A.; Karthi, S.; Palanikani, R.; Shyam Sundar, N.; Sivanesh, H.; Soranam, R.; Senthil-Nathan, S. Sustainable agronomic strategies for enhancing the yield and nutritional quality of wild tomato, Solanum Lycopersicum (1) var Cerasiforme Mill. Agronomy 2019, 9, 311. [CrossRef]

36. Michalska-Ciechanowska, A.; Wojdyło, A.; Bogucka, B.; Dubis, B. Moderation of inulin and polyphenolics contents in three cultivars of Helianthus tuberosus L. by potassium fertilization. Agronomy 2019, 9, 884. [CrossRef]

37. Guijarro-Real, C.; Adalid-Martínez, A.M.; Aguirre, K.; Prohens, J.; Rodríguez-Burruezo, A.; Fita, A. Growing conditions affect the phytochemical composition of edible Wall Rocket (Diplotaxis erucoides). Agronomy 2019, 9, 858. [CrossRef]

38. Dwivedi, S.; Goldman, I.; Ortiz, R. Pursuing the potential of heirloom cultivars to improve adaptation, nutritional, and culinary features of food crops. Agronomy 2019, 9, 441. [CrossRef]

39. Borelli, T.; Hunter, D.; Padulosi, S.; Amaya, N.; Meldrum, G.; Beltrame, D.M.D.O.; Samarasinghe, G.; Wasike, V.W.; Güner, B.; Tan, A.; et al. Local solutions for sustainable food systems: The contribution of orphan crops and wild edible species. Agronomy 2020, 10, 231. [CrossRef]

40. Singh, A.; Dubey, P.K.; Chaurasia, R.; Dubey, R.K.; Pandey, K.K.; Singh, G.S.; Abhilash, P.C. Domesticating the undomesticated for global food and nutritional security: Four steps. Agronomy 2019, 9, 491. [CrossRef] 